\title{
Las franquicias en México en 1999 y 2007
}

Fecha de recepción: 10.10.2008

Fecha de aceptación: 12.11.2009

Ma. Cristina Alba Aldave Investigadora, División de Investigación, Facultad de Contaduría y Administración, UNAM._crialba@correo.fca. unam.mx

\section{Resumen}

La información económica generada sobre el mercado de franquicias en México es deficiente porque no existe una institución u organismo que ofrezca cifras confiables y suficientes en las que sea posible apreciar la dinámica y volumen total del mercado. El objetivo de esta investigación es determinar el crecimiento, el cambio en la estructura y características de las franquicias de México en 1999 y 2007. Para ello se recopiló y sistematizó información de 720 empresas mediante la revisión de fuentes especializadas del tema, visitas a empresas y entrevistas a franquiciatarios y franquiciantes con lo que se estructuró una base de datos. Entre los principales resultados se encontró un cambio de estructura donde las franquicias mexicanas crecen y las extranjeras disminuyen, especialmente las de Estados Unidos. El cambio de cultura empresarial parece positivo para aquellos que desarrollaron franquicias en México $\mathrm{y}$ ahora las exportan, pero las franquicias extranjeras de comida rápida perjudican la salud de la población y no promueven la formación de proveedores locales.

Palabras clave: franquicias, México, base de datos. 


\title{
Franchises in Mexico in 1999 y 2007
}

\begin{abstract}
Economic information about the mexican franchise market is limited and lack of quality thereford it is not possible to know it's dynamic of grow, the market structure and characteristics. The present research has as main objective to determinate the gowing rate changes in market structure and characteristica of the franchises in México between 1999 and 2007. Information about 720 companies was compiled after consulting secondary informtion and interviewing companies. The information was systematized and a data base structured. We found that mexican franchises grew while the franchises from the United State decreased. Cultural changes from entrepreneurs are favorables but fast food franchises are changing cultural eating habits and not allow the formation of value chains with local suppliers.
\end{abstract}

Keywords: franchises, Mexico, data base.

\section{Introducción}

La franquicia encuentra su principal regulación en la Ley de la Propiedad Industrial, que en su Artículo 142 la define de la siguiente forma:

La franquicia es una estrategia de negocios que se basa en un sistema de comercialización y prestación de servicios donde el franquiciante ofrece a través de un contrato, la autorización para la distribución, producción y venta exitosa de bienes y servicios al franquiciatario por un periodo determinado. (1994:31)

El Reglamento de la Ley de la Propiedad Industrial, publicado el 23 de noviembre de 1994, integra las reformas que ésta ha sufrido desde que fue sancionada en 1991. En él se define a las partes que integran el contrato de franquicias: el franquiciante y el franquiciatario.

Por una parte, el franquiciante es el poseedor del sistema operativo de un negocio exitoso, que incluye una marca, nombre comercial, tecnología o conocimientos necesarios para la explotación de un producto, prestación de un servicio y un proceso o bien, todos en conjunto. El franquiciatario es la persona que adquiere el sistema operativo y recibe los conocimientos que el franquiciante le confía para dar a la unidad franquiciada los estándares de calidad del producto o servicio que ofrece la franquicia maestra. Es decir, el franquiciante es la persona que otorga los dere- 
chos sobre sus productos o servicios, mientras que a la persona que los recibe se le denomina franquiciatario. Todos los requisitos que se exigen para la operación de ambas partes quedan registrados en un contrato.

Durante el primer semestre del 2008 se generó en el sector de franquicias, por concepto de ventas al consumidor final, un monto de 30 mil millones de pesos, lo cual representó 6\% del Producto Interno Bruto (PIB) mexicano. Para finales de 2009, la Asociación Mexicana de Franquicias (AMF) estima que las ventas serán superiores a los 80 mil millones de pesos (AMF, 2009) ${ }^{1}$

En el 2007, México ocupó el lugar siete en el ranking internacional de franquicias emitido por la World Franchise Council. Esta clasificación considera criterios como número de unidades de negocio abiertas en cada país, antigüedad en el organismo, número de franquicias certificadas, la instrumentación de programas educativos y de capacitación, el apoyo gubernamental y el número de franquicias exportadas. ${ }^{2}$ En los diez primeros lugares de dicho ranking se ubican: Estados Unidos, Brasil, Canadá, Japón, Francia, España, México, Australia, Alemania e Italia $^{3}$. Sin embargo, de acuerdo con datos del Instituto Mexicano de la Producción Industrial (IMPI), se registraron tan sólo 1088 contratos inscritos bajo el término de franquicias durante 2007, número relativamente bajo si se tiene en cuenta que la AMF reconoce 750 empresas franquiciantes. ${ }^{4}$

Se estima que de las 750 franquicias reportadas por la AMF $70 \%$ cumplen estrictamente con las cualidades de este formato de negocios, mientras el restante $30 \%$ son más bien "oportunidades de negocio". La diferencia entre estas dos modalidades es que en la franquicia se brinda una asesoría técnica siempre que sea requerida mientras que en la "oportunidad de negocio" no existe este servicio. Además, en esta úlitma modalidad el vendedor provee el establecimiento y la operación comienza hasta que se ha otorgado el punto de venta. Podemos decir que en términos absolutos el mercado de franquicias en México oscila entre 500 y 550 franquicias.

\footnotetext{
${ }^{1}$ Para mayor amplitud véase el sitio web de la Asociación Mexicana de Franquicias: http://www.franquiciasdemexico.org/index.php?idsec=22 (consultado el 15 de marzo de 2009)

${ }^{2}$ Esta información se obtuvo de la página: http://www.worldfranchisecouncil.org y en http://www.soyentrepreneur.com/home/index.php?p=nota\&idNota=5481 ( consultado el 15 de marzo de 2009)

${ }^{3}$ Cabe mencionar que el ranking de la WFC está integrado por 33 países

${ }^{4}$ Ver: www.impi.gob.mx
} 
El mercado cuenta con distinciones que buscan garantizar la calidad en la operación de las distitnas unidades de negocio. La Asociación Mexicana de Franquicias (AMF) en conjunto con la empresa Calidad Mexicana Certificada (Calmecac) han creado el denominado "Sello de Calidad", cuyo principal objetivo es ordenar el mercado e impulsar la actividad franquiciataria otorgando credibilidad y confianza a las franquicias e inversionistas potenciales.

Como ya se mencionó, la figura de la franquicia en México se sustenta básicamente en dos artículos: el 142 de la Ley de la Propiedad Industrial y el 65 de su Reglamento. Sin embargo, dicho marco jurídico se enmarca de manera general en la Constitución de la República Mexicana, en los artículos 25 y 28 del Código de Comercio, en el Código Civil Federal, en la Ley de la Propiedad Industrial, en la Ley de Derecho de autor, en la Ley de Sociedades Mercantiles, en la Legislación Fiscal, en la Ley del Trabajo en la Ley de Protección al Consumidor y en la Ley de Competencia Económica.

Cabe mencionar que la ley mexicana obliga a los franquiciatarios (nacionales o extranjeros) a entregar la Circular de Oferta de Franquicia (COF) a todos aquellos interesados en adquirir la licencia de una franquicia. Éste es el documento que todo franquiciatante debe cumplir de acuerdo con la Ley de la Propiedad Industrial.

Por su parte, el contrato de franquicia procura que la persona a la que se le concede la licencia de franquicia pueda vender bienes o prestar servicios con los métodos operativos, comerciales y administrativos establecidos por el titular de la marca con base en el contrato de particulares.

\section{Planteamiento del problema y pregunta de investigación}

La información económica generada sobre el mercado de franquicias en México es deficiente porque no existe una institución u organismo que ofrezca cifras exactas y suficientes en las que sea posible apreciar la dinámica y volumen total del mercado, lo que representa una problema, pues es imposible calcular en términos monetarios la importancia y aportación real que tienen las franquicias en la economía mexicana. En este sentido, los cálculos referentes a la participación de las franquicias en relación con el monto total del PIB nacional son aproximaciones que erróneamente instituciones como la AMF e incluso la Secretaría de Economía consideran válidas para la toma de decisiones y para la aplicación de planes y estrategias enfocadas al desarrollo del mercado. 
Por su parte, la AMF sólo ofrece información de las franquicias afiliadas a ella; asimismo, en estos registros es imposible detectar variables que permitan profundizar en el estudio del mercado de franquicias de forma significativa. Por otro lado, los registros de la Secretaría de Economía mostrados a través del Sistema de Información Empresarial no diferencian la figura de franquicia de la figura de pequeña y mediana empresa nacional o extranjera, por lo que se vuelve imposible el estudio de índices de productividad.

Debido a que los datos que la Secretaría de Economía y la AMF presentan sobre franquicias en México difieren, en este trabajo nos preguntamos ¿cuál ha sido el desarrollo del mercado de franquicias mexicano en los años 1999 y 2007 en relación con el su evolución cuantitativa de crecimiento, estratificado por giros, países poseedores del capital de origen de las franquicias, así como la tasa de crecimiento?

\section{Objetivo del estudio}

Nuestro objetivo es conocer la situación en la que se encuentra el mercado de franquicias mexicano en lo que se refiere al desarrollo cuantitativo de las franquicias maestras identificando también aspectos cualitativos durante el periodo de estudio (1999-2007). Especialmente nos interesa conocer cuántas franquicias existen por cada giro, determinar los cambios en estructura y sus características.

\section{Metodología}

Por las características del estudio, se trata de una investigación exploratoria porque no se tiene conocimiento acerca de hallazgos en estudios anteriores en los que se analice la orientación y preferencia de los consumidores en lo que respecta al mercado de franquicias, salvo un estudio realizado hace más de diez años por el periódico Reforma, el cual fue elaborado sólo en una ocasión.

Se trata de una investigación documental en torno al desarrollo cuantitativo del mercado mexicano en el que se analiza su composición. Durante el proceso de investigación fue necesario revisar directorios mundiales de franquicias, visitar distintas ferias nacionales e internacionales, consertar entrevistas con franquiciantes y franquiciatarios, así como consultar periódicamente páginas web de franquicias con el fin de garantizar información veraz y confiable. Asimismo, se trata de un diseño de tipo longitudinal o evolutivo porque recopila información a lo largo de los años 1999 y 2007. 
Además, es un estudio sistemático. El principal recurso de investigación que sustenta este documento es la base de datos elaborada por cuenta propia durante el periodo de estudio. Ésta hace referencia a la composición cuantitativa del mercado mexicano, pues su estructura permite un análisis de cada giro del mercado, así como identificar el número total de franquicias y el tipo de inversión de cada franquicia (mexicana o extranjera). Cabe mencionar que el nombre de los grupos de franquicias, giros y la asignación de cada franquicia en ellos, fue considerando como principal aspecto la actividad comercial de las unidades de negocio.

La base de datos fue elaborada en función de las siguientes tres variables: 1) Giros, los cuales fueron: Alimentos y restaurantes; Servicios; Cuidado personal y niños; Educación; Tiendas convencionales y de especialidad; Bienes raíces; Cartuchos y reciclaje; Dulces y reglalos; Fotografía, video y libros; Mascotas; Seguridad; Mensajería; Renta de autos; Mueblería; Reparación, calzado y ropa; Construcción y vivienda; Decoración y remodelación; Diversión y entretenimiento; Hoteles y moteles; Imprentas y publicidad; Mantenimiento, hogar, oficina y limpieza; Ropa y accesorios; Salud; Taller de servicio automotriz; Tintorería y lavandería; y Otros. 2) Origen de la inversión la cual puedeser mexicana o extranjera: Estados Unidos y otros países. 3) Tasa de crecimiento, que se refiere a la cantidad de franquicias en cada año y origen de la inversión.

Cabe mencionar que la principal limitante en esta investigación es la imposibilidad de contar con información relevante, en serie de datos de tiempo o información estadistica, relacionada con el número de empleos, el monto de venta, costo de mercancía, fuga de divisas, pago de regalías, sólo por mencionar algunos aspectos entre los más importantes.

\section{Resultados de la investigación}

Los resultados obtenidos de la investigación se registran en el cuadro 1: 


\section{Cuadro 1}

Mercado de franquicias mexicano en los periodos 1999 y 2007 (agrupado por los principales giros y el origen de capital)

\begin{tabular}{|c|c|c|c|c|c|c|c|c|c|c|c|}
\hline & 1999 & 2007 & & 1999 & 2007 & & 1999 & 2007 & & 1999 & 2007 \\
\hline GIRO & \multicolumn{2}{|c|}{ México } & T.C.* & \multicolumn{2}{|c|}{ EUA } & T.C.* & \multicolumn{2}{|c|}{ Otros } & T.C.* & \multicolumn{2}{|c|}{$\begin{array}{c}\text { Total de } \\
\text { franquicias }\end{array}$} \\
\hline \multicolumn{12}{|l|}{$\begin{array}{l}\text { Alimentos y } \\
\text { restaurantes }\end{array}$} \\
\hline Cafeterías & 10 & 13 & $30 \%$ & 12 & 8 & $-33 \%$ & 2 & 2 & 0 & 24 & 23 \\
\hline $\begin{array}{c}\text { Comida rápida } \\
\text { extranjera }\end{array}$ & 16 & 18 & $13 \%$ & 69 & 36 & $-48 \%$ & 6 & 6 & 0 & 91 & 60 \\
\hline $\begin{array}{c}\text { Comida rápida } \\
\text { nacional }\end{array}$ & 10 & 15 & $50 \%$ & 7 & 3 & $-57 \%$ & 0 & 0 & 0 & 17 & 18 \\
\hline Helados & 7 & 18 & $157 \%$ & 8 & 11 & $38 \%$ & 2 & 2 & 0 & 17 & 31 \\
\hline $\begin{array}{l}\text { Misceláneos, } \\
\text { alimentos }\end{array}$ & 4 & 12 & $200 \%$ & 4 & 14 & $N . R^{* *}$ & 1 & 2 & $N . R^{* *}$ & 9 & 28 \\
\hline Panadería & 2 & 12 & $N . R^{* *}$ & 10 & 11 & $10 \%$ & 1 & 0 & -100 & 13 & 23 \\
\hline $\begin{array}{c}\text { Restaurantes y } \\
\text { bares }\end{array}$ & 25 & 42 & $68 \%$ & 24 & 10 & $-58 \%$ & 2 & 2 & 0 & 51 & 54 \\
\hline Subtotal & 74 & 130 & & 134 & 93 & & 14 & 14 & & 222 & 237 \\
\hline \multicolumn{12}{|l|}{ Servicios } \\
\hline $\begin{array}{c}\text { Servicios } \\
\text { empresariales }\end{array}$ & 8 & 8 & $0 \%$ & 28 & 16 & $-43 \%$ & 2 & 2 & 0 & 38 & 26 \\
\hline $\begin{array}{c}\text { Servicios } \\
\text { financieros }\end{array}$ & 4 & 18 & $350 \%$ & 1 & 1 & $0 \%$ & 0 & 0 & 0 & 5 & 19 \\
\hline Servicio de viajes & 0 & 7 & $100 \%$ & 4 & 1 & $-75 \%$ & 0 & 0 & 0 & 4 & 8 \\
\hline Computación & 1 & 6 & $500 \%$ & 3 & 1 & $-67 \%$ & 0 & 2 & N.R** & 4 & 9 \\
\hline Subtotal & 13 & 39 & & 36 & 19 & & 2 & 4 & & 51 & 62 \\
\hline \multicolumn{12}{|l|}{ Cuidado personal } \\
\hline $\begin{array}{c}\text { Artículos y } \\
\text { servicios para niños }\end{array}$ & 4 & 3 & $-25 \%$ & 17 & 14 & $-18 \%$ & 3 & 4 & $33 \%$ & 24 & 21 \\
\hline $\begin{array}{l}\text { Belleza y cuidado } \\
\text { personal }\end{array}$ & 7 & 9 & $29 \%$ & 22 & 20 & $-9 \%$ & 3 & 7 & N.R** & 32 & 36 \\
\hline Subtotal & 11 & 12 & & 39 & 34 & & 6 & 11 & & 56 & 57 \\
\hline \multicolumn{12}{|l|}{ Educación } \\
\hline $\begin{array}{c}\text { Capacitación y } \\
\text { educación }\end{array}$ & 4 & 16 & $300 \%$ & 21 & 15 & $-29 \%$ & 4 & 7 & $75 \%$ & 29 & 38 \\
\hline Subtotal & 4 & 16 & & 21 & 15 & & 4 & 7 & & 29 & 38 \\
\hline \multicolumn{12}{|l|}{$\begin{array}{c}\text { Tiendas } \\
\text { convencionales y de } \\
\text { especialidades }\end{array}$} \\
\hline $\begin{array}{c}\text { Tienda } \\
\text { convencional }\end{array}$ & 6 & 7 & $17 \%$ & 2 & 3 & $50 \%$ & 0 & 0 & 0 & 8 & 10 \\
\hline $\begin{array}{c}\text { Tienda de } \\
\text { especialidades }\end{array}$ & 9 & 10 & $11 \%$ & 16 & 10 & $-38 \%$ & 0 & 0 & 0 & 25 & 20 \\
\hline Subtotal & 15 & 17 & & 18 & 13 & & 0 & 0 & & 33 & 30 \\
\hline \multicolumn{12}{|l|}{ Otros } \\
\hline Bienes raíces & 0 & 4 & $N . R^{* *}$ & 4 & 8 & $100 \%$ & 0 & 0 & 0 & 4 & 12 \\
\hline $\begin{array}{l}\text { Cartuchos y } \\
\text { reciclaje }\end{array}$ & 0 & 1 & $N . R^{* *}$ & 0 & 3 & $N . R^{* *}$ & 0 & 1 & N.R** & 0 & 5 \\
\hline
\end{tabular}




\section{Continuación cuadro 1}

\begin{tabular}{|c|c|c|c|c|c|c|c|c|c|c|c|}
\hline & 1999 & 2007 & & 1999 & 2007 & & 1999 & \begin{tabular}{|l|}
2007 \\
\end{tabular} & & 1999 & 2007 \\
\hline GIRO & \multicolumn{2}{|c|}{ México } & T.C.* & \multicolumn{2}{|c|}{ EUA } & T.C.* & \multicolumn{2}{|c|}{ Otros } & T.C.* & \multicolumn{2}{|c|}{$\begin{array}{c}\text { Total de } \\
\text { franquicias }\end{array}$} \\
\hline Dulces y regalos & 1 & 11 & $N . R^{* *}$ & 12 & 2 & $-83 \%$ & 0 & 1 & $100 \%$ & 13 & 14 \\
\hline $\begin{array}{c}\text { Fotografía, video y } \\
\text { libros }\end{array}$ & 0 & 2 & $N . R^{* *}$ & 3 & 2 & $-33 \%$ & 0 & 1 & $100 \%$ & 3 & 5 \\
\hline Mascotas & 0 & 1 & $N . R^{* *}$ & 0 & 3 & $N . R^{* *}$ & 0 & 1 & $100 \%$ & 0 & 5 \\
\hline Varios & 4 & 2 & $-50 \%$ & 3 & 0 & $-100 \%$ & 0 & 0 & 0 & 7 & 2 \\
\hline Seguridad & 3 & 1 & $-67 \%$ & 0 & 7 & $N . R^{*}$ & 0 & 0 & 0 & 3 & 8 \\
\hline Mensajería & 2 & 4 & $100 \%$ & 8 & 5 & $-38 \%$ & 0 & 0 & 0 & 10 & 9 \\
\hline Renta de autos & 2 & 1 & $-50 \%$ & 7 & 6 & $-14 \%$ & 0 & 0 & 0 & 9 & 7 \\
\hline Mueblería & 4 & 2 & $-50 \%$ & 1 & 0 & $-100 \%$ & 0 & 0 & 0 & 5 & 2 \\
\hline $\begin{array}{c}\text { Reparación, calzado } \\
\text { y ropa }\end{array}$ & 0 & 6 & $N . R^{* * *}$ & 2 & 2 & 0 & 1 & 0 & $N . R^{* *}$ & 3 & 8 \\
\hline Subtotal & 16 & 35 & & 40 & 38 & & 1 & 4 & & 57 & 77 \\
\hline $\begin{array}{c}\text { Construcción y } \\
\text { vivienda }\end{array}$ & 4 & 4 & 0 & 7 & 4 & $-43 \%$ & 1 & 0 & $-100 \%$ & 12 & 8 \\
\hline $\begin{array}{l}\text { Decoración y } \\
\text { remodelación }\end{array}$ & 6 & 6 & 0 & 20 & 13 & $-35 \%$ & 0 & 1 & $N . R^{* *}$ & 26 & 20 \\
\hline $\begin{array}{c}\text { Diversión y } \\
\text { entretenimiento }\end{array}$ & 14 & 14 & 0 & 10 & 2 & $-80 \%$ & 1 & 3 & $200 \%$ & 25 & 19 \\
\hline Hoteles y moteles & 1 & 2 & $N . R^{* *}$ & 19 & 2 & $-89 \%$ & 0 & 0 & 0 & 20 & 4 \\
\hline $\begin{array}{l}\text { Imprentas y } \\
\text { publicidad }\end{array}$ & 3 & 9 & $200 \%$ & 9 & 13 & $44 \%$ & 0 & 0 & 0 & 12 & 22 \\
\hline $\begin{array}{c}\text { Mantenimiento, } \\
\text { hogar, oficina y } \\
\text { limpieza }\end{array}$ & 4 & 5 & $25 \%$ & 34 & 31 & $-9 \%$ & 0 & 1 & $100 \%$ & 38 & 37 \\
\hline Ropa y accesorios & 15 & 14 & $-7 \%$ & 2 & 6 & $200 \%$ & 0 & 6 & $100 \%$ & 17 & 26 \\
\hline Salud & 5 & 21 & $320 \%$ & 14 & 13 & $-7 \%$ & 0 & 1 & $100 \%$ & 19 & 35 \\
\hline $\begin{array}{c}\text { Taller y servicio } \\
\text { automotriz }\end{array}$ & 7 & 10 & $43 \%$ & 34 & 19 & $-44 \%$ & 1 & 4 & $300 \%$ & 42 & 33 \\
\hline $\begin{array}{l}\text { Tintorería y } \\
\text { lavandería }\end{array}$ & 4 & 7 & $75 \%$ & 7 & 5 & $-29 \%$ & 0 & 3 & N.R** & 11 & 15 \\
\hline TOTAL & 196 & 341 & & 444 & 320 & & 30 & 59 & & 670 & 720 \\
\hline
\end{tabular}

Fuente:Elaboración propia con información de la base de datos creada Nota: * T.C. Tasa de Crecimiento **N.R. No Representativo

En el cuadro 1 se observa que en 1999 el mercado mexicano de franquicias se encontraba integrado por 444 franquicias con capital norteamericano (lo cual representaba 66\% del mercado), 196 franquicias de origen mexicano (aproximadamente el 29\%) y sólo 30 franquicias de otros países (un restante 5\%). 
En ese año las franquicias de capital de origen mexicano se encontraban en una situación minoritaria, en términos cuantitativos, respecto a las franquicias extranjeras. Sin embargo, para 2007 se presentó un crecimiento de las franquicias mexicanas en aproximadamente $73 \%$ (véase el cuadro 2). Las franquicias norteamericanas redujeron su participación en un $38 \%$ en relación con 1999, mientras que el resto de las franquicias extranjeras mostraron un aumento del $50 \%$.

\section{Cuadro 2}

Número de franquicias en los años 1999-2007

\begin{tabular}{|c|c|c|c|}
\hline Nacionalidad & $\mathbf{1 9 9 9}$ & $\mathbf{2 0 0 7}$ & Tasa de crecimiento \\
\hline México & 196 & 341 & $73 \%$ \\
\hline EE.UU. & 444 & 320 & $-38 \%$ \\
\hline Otra & 30 & 59 & $50 \%$ \\
\hline Total & 670 & 720 & \\
\hline
\end{tabular}

Fuente: Elaboración propia con información de la base de datos creada

De acuerdo con el cuadro 1, para finales del año 2007 los giros con mayor cantidad de franquicias eran: Alimentos y restaurantes (222) —en el cual destacan los giros de comida rápida extranjera (91) — Restaurantes y bares (52), Cafeterías (24), Comida rápida nacional (17); en un segundo plano el giro de Belleza y cuidado personal (32), Educación (29) y Tiendas de especialidad (25). Es por ello que a continuación se analiza la composición de estos giros a lo largo del periodo de estudio.

\section{Alimentos y restaurantes}

Este grupo es de gran importancia porque en su conjunto representa $33 \%$ del mercado en ambos años. Está integrado por franquicias dedicadas al negocio de cafeterías, comida rápida extranjera, comida rápida nacional, helados, misceláneas, panaderías, restaurantes y bares.

En 1999 este segmento estaba compuesto en su mayoría por franquicias norteamericanas (134 unidades de 222). Sin embargo, para 2007 las franquicias nacionales mostraron un incremento cuantitativo alcanzando una participación de 130 unidades que corresponde a $54 \%$ dentro del grupo de alimentos y restaurantes y las franquicias de capital de origen mexicano dedicadas a esta actividad representan el $18 \%$ del mercado de franquicias. 
El incremento de este grupo se debió principalmente al aumento en la participación de franquicias mexicanas dedicadas al giro de comida rápida extranjera, restaurantes y bares, panaderías, misceláneos y helados (ver gráfica 1).

\section{Gráfica 1}

Composición por giro de franquicias en el grupo de Alimentos y restaurantes en 2007

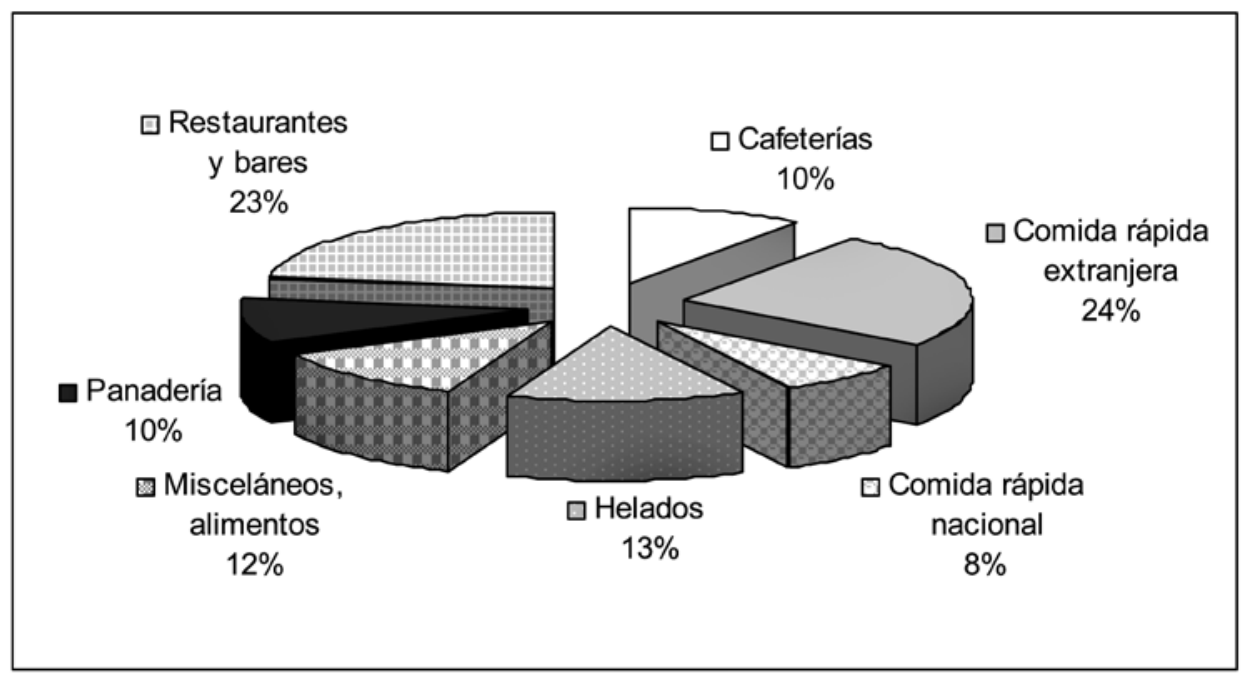

Fuente:Elaboración propia con información de la base de datos creada

El número de empresas de comida rápida extranjera en el país refleja una clara penetración cultural en la que influye fenómenos como la globalización y la tropicalización de los servicios y productos. Estos giros han puesto especial énfasis en la sistematización y homogeneidad del servicio, lo que facilita venderlas con procesos estandarizados como es el caso de Las Gaoneras, Mc Donald's y Sushi Itto. Además, éste es uno de los giros que tienen mayor número de franquicias con certificación de calidad. Sin embargo, la comida rápida está relacionada con problemas salud de la población como es la obesidad y diabetes.

\section{Servicios}

Este grupo mostró un comportamiento destacable (ver gráfica 2). Las franquicias de origen nacional aumentaron su número tres veces en relación con 1999. Este 
grupo se encuentra constituido por franquicias dedicadas a los servicios empresariales, financieros, de viajes y de computación.

Para 2007, el renglón de Servicios representó 9\% del mercado (con 62 franquicias). En términos porcentuales este grupo se integró mayoritariamente por franquicias de capital de origen nacional con $62 \%$, mientras que las norteamericanas representaron aproximadamente $30 \%$; el restante $8 \%$ fue dado por franquicias originarias de otros países. Si se contempla la totalidad del mercado se encuentra que las franquicias mexicanas, en este grupo, representan aproximadamente $5 \%$ para el año 2007.

Gráfica 2

Composición por origen de inversión del segmento de Servicios en México

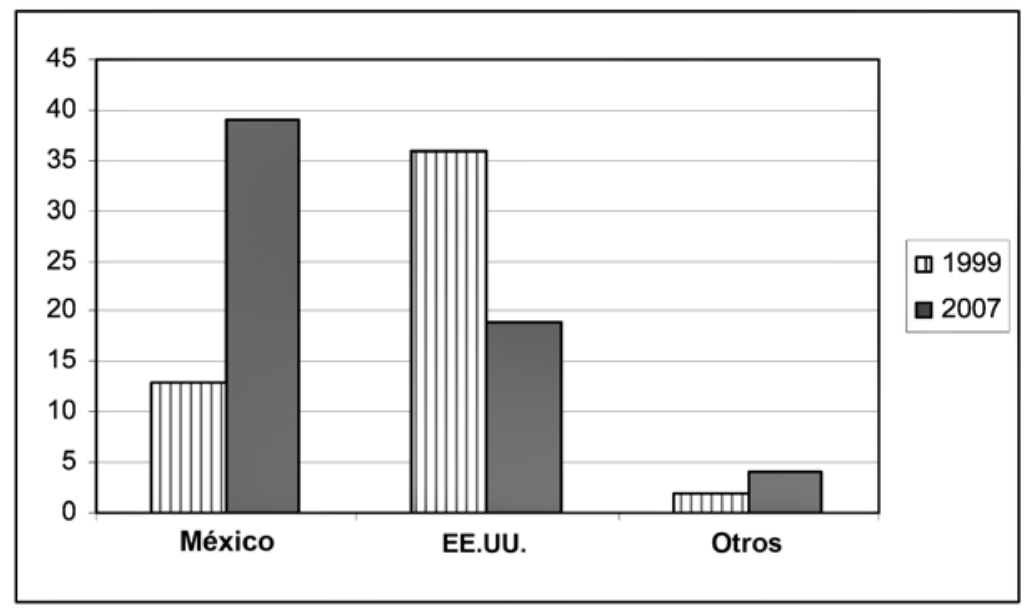

Fuente: Elaboración propia con información de la base de datos creada

\section{Educación}

Este grupo está integrado por franquicias dedicadas a actividades de enseñanza de idiomas, habilidades técnicas, educación para niños y capacitación.

En este giro se gestó un desarrollo favorable para las franquicias de origen de capital mexicano porque en 2007 aumentaron su participación cuatro veces en relación con 1999; en contraparte las franquicias de origen estadounidense disminuyeron 
aproximadamente $33 \%$ su participación, mientras que las franquicias de otros países aumentaron su participación cuatro puntos porcentuales.

\section{Gráfica 3}

Composición del giro de Educación por origen de la inversión

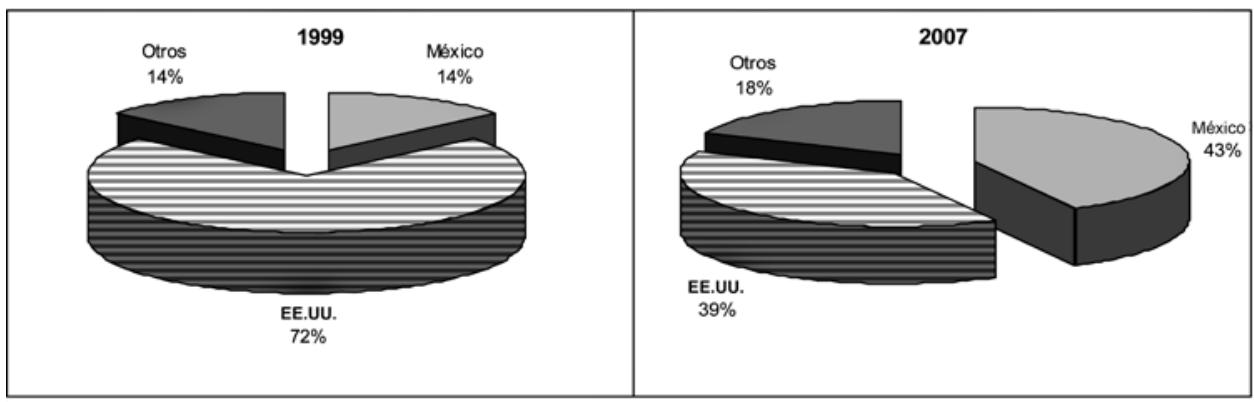

Fuente: Elaborado con información de la Base de Datos

\section{Cuidado personal}

El giro de Cuidado personal no muestra un comportamiento favorable para las empresas mexicanas; únicamente existen aumentos en las franquicias de otros países. Sin embargo, este giro es de importancia en el mercado mexicano, puesto que está compuesto por 57 franquicias, lo cual representa casi el $8 \%$ del total de las franquicias. El mercado del cuidado de la apariencia física ha tenido una tendencia a la alza porque orienta al consumidor hacia una vida más saludable optando por soluciones que hagan bajar de peso en un corto periodo y con poco esfuerzo. Actualmente, el desarrollo del giro de Belleza y cuidado personal es incierto debido a la difícil situación económica, la cual puede generar cambios en este giro haciendo que disminuya la demanda para las empresas dedicadas al Cuidado personal o bien que el segmento busque actividades suplementarias de bajo costo (como salir a correr o hacer ejercicio en casa). Es necesario dar seguimiento al comportamiento de este giro para comprender su orientación y desarrollo ante la crisis.

Los aportes de las franquicias al incremento del empleo son reducidos porque en promedio cada unidad emplea nueve personas que trabajan seis días a la semana y reciben salario mínimo mensual. Asimismo, la mano de obra requerida no està bien capacitada porque el trabajo se encuentra muy fragmentado y los cursos se enfocan en un solo proceso. En este sentido la circular de oferta señala que no se 
requieren franquiciatarios con conocimientos del negocio debido a que la franquicia maestra no quiere que se conviertan en competidores en el futuro.

\section{Conclusiones}

A finales de 2007 se revisaron 720 franquicias en las que se encontraron cambios en su estructura y características. Las franquicias de capital de origen nacional incrementaron su participación en 1999 y 2007, alcanzando 47\% del mercado; por su parte, las franquicias de origen de capital estadounidense disminuyeron su participación $45 \%$ y las de capital de otros países aumentaron su presencia en el mercado para alcanzar $8 \%$.

Es posible afirmar que el mercado mexicano está en crecimiento y cuenta con elementos tales como la certificación, créditos bancarios y estímulos gubernamentales, los que favorecen su desarrollo y capacidad de afrontar adversidades como la crisis global que actualmente ha impactado diversas industrias en México. Por tal motivo es que las franquicias de origen mexicano se perfilan como una atractiva opción para los inversionistas debido al bajo riesgo que representa esta modalidad de negocios en comparación a la ardua tarea de emprender un negocio por cuenta propia.

Sin embargo, los beneficios para la economía son discutibles debido a que las cadenas productivas de franquicias extranjeras tienen generalmente proveedores extranjeros; por lo tanto, no se permite el desarrollo de empresas locales para surtir materias primas.

Entre las ventajas que las franquicias ofrecen a la economía mexicana se pueden considerar que aquéllas que son de origen mexicano exportan a otros países cuando han madurado. Considerando siempre la uniformidad en el servicio y la calidad en los productos, los empresarios han logrado, en una primera etapa, consolidarse en el mercado mexicano y posteriormente exportar la marca. En ese sentido se han logrado cambios en la cultura empresarial, por ejemplo, con el nacimiento de cadenas de proveedores en diversos restaurantes de franquicias.

La influencia cultural de las franquicias también se refleja en cambios en la ideología de la clase empresarial y conductas de los consumidores. Los franquiciatarios constituyen un segmento especial dentro de la clase empresarial; son personas que buscan beneficios económicos, basando sus decisiones en los niveles de rentabi- 
lidad, financiamiento, experiencia internacional y grado tecnológico aplicado a la franquicia. Debido a una exitosa penetración cultural es que las empresas franquiciantes se han constituido en el mercado cambiando los hábitos y costumbres de los consumidores, sobre todo en la materia de alimentación con la comida rápida, con lo que han logrado así variaciones en la sociedad urbana. Su objetivo se orienta hacia la uniformidad de los hábitos culturales del consumidor.

La mayoría de franquicias extranjeras asentadas en México producen un efecto de aculturación. Sin embargo, al paso del tiempo las nuevas generaciones probablemente se encontrarán ya enculturizadas con la franquicias de hoy ${ }^{5}$.

La situación deseable sería contar con un mayor número de empresarios mexicanos que tuvieran la capacidad de fortalecer sus negocios y crear franquicias nacionales en vez de comprar una extranjera, con ello se tendrían mayores beneficios de los cuales el principal sería la reinversión del capital generado en México por venta al consumidor final de la franquicia.

\section{Referencias}

Alba Aldave, Cristina (2006). "Técnicas efectivas de ventas", Emprendedores No. 98. marzo-abril. Fondo Editorial FCA, UNAM, México.

(2002). “¡Todo sobre franquicias!”. Emprendedores No. 77. septiembre-octubre, Fondo Editorial FCA, UNAM, México.

Asociación Mexicana de Franquicias (1996). Directorio de socios. Segundo Semestre de 96. México.

Asociación Mexicana de Franquicias, "Estadísticas". Sitio web: http://www. franquiciasdemexico.org/index.php?idsec $=22$

\footnotetext{
${ }^{5}$ La cultura se puede entender como el conjunto de valores, creencias y normas que rigen a los miembros de una sociedad. Se tiene que la enculturalización es el primer punto de aprendizaje dentro de la formación de una persona. La cultura nos muestra las pautas para elegir la conducta adecuada o la sancionada por la sociedad. Si se considera que una persona va a vivir a un país extranjero, ésta puede aprender las normas, valores y conductas de la cultura en la que vive; a este fenómeno se le llama aculturización y aunque adopte diferentes conductas, la persona continuará siendo ella misma: sus conceptos culturales no cambiarán. Dicha situación es aplicable a las personas y empresas. Por tanto, un franquicia extranjera debe hacer ciertas variantes para satisfacer exitosamente las necesidades de un nuevo mercado; a esto se le llama tropicalización.
} 
Barbadillo de María, Santiago (1999). La franquicia paso a paso. $2^{a}$ ed., Madrid: De Franquicia, S.L., 217 pp.

Cherto, Marcelo "De la adolescencia a la madurez". Entrepreneur, No. 1, Vol. 12.

De Pina, Rafael (1999). Derecho Mexicano Civil. $9^{a}$ ed., México.

Dí Costanzo, Juan, Alejandra Vilalta y Donato Cárdenas (1997). Desarrollo de Sistemas de Franquicias, México: McGraw Hill, 140 pp.

Directory of Franchising Organizations (1998). The franchising today series. Estados Unidos: Pilot Books.

EnRico, Roger y Jesse Kornbluth. (1997). La guerra de las colas. $2^{\mathrm{a}}$ ed., Segunda de Bolsillo, Colombia: Grupo Editorial Nor.

Entrepreneur (2003). "500 franquicias en México". 10ª ed., Vol. 11 No. 1, enero, México. 87 pp.

(2002). "500 franquicias en México". 9a ed., Vol. 10, No. 1, enero, México, 67 pp.

ENTREPRENEUR Revista EleCtróniCa http://www.soyentrepreneur.com/home/ index.php?p=nota\&idNota=5481(consul-tado el 15 de marzo de 2009)

EXPANSIÓN (2002). "Las 500 empresas más importantes de México". julio 20. No. 845, México, 340 pp.

Ferenz Tocalli, Feher (2006) Franquicias \$=éxito, motivo y razones, febrero. México: Santillana Express, 196 pp.

(1999). Franquicias a la mexicana: Hablemos de franquicias con franqueza, México: McGraw Hill, 76 pp.

FRANCO, RAFAel (2006). “Año de madurez para las franquicias”. Franquicias y Negocios, Año 1, Vol. 13, Ed. Objetivos Ad Hoc, marzo, México, 118 pp. 
(2006). "En puntos suspensivos, el programa Credifranquicias", Franquicias y Negocios, Año 2, No. 15, Ed. Objetivos Ad Hoc, mayo, México, $138 \mathrm{pp}$.

(2005). "Franquicias, engranaje de la economía mexicana". Franquicias y Negocios, Año 1, No. 15, Ed., Objetivos Ad Hoc, octubre, México, $108 \mathrm{pp}$.

González Calvillo, Enrique y Rodrigo González Calvillo (1994) Franquicias: La revolución de los 90's, México: Mc Graw Hill.

Instituto Mexicano de La Propiedad Industrial (IMPI) sitio web: www.impi. gob.mx [Fecha de consulta: 15 de marzo 2009].

Ley de la Propiedad Industrial, (1994) Agenda Mercantil, México: ISEF, pp. 31.

"Operan 750 franquicias en México, sólo 19 tienen certificación” jornada.unam. mx. PyMES Pequeñas y Medianas Empresas. Sitio web: http://www.jornada.unam.mx/2007/07/04/index.php?section=economia\&article=028n2eco [Fecha de consulta: 15 de marzo de 2009].

Programa Nacional de Franquicias, Secretaría de Economía. Fecha de Publicación: septiembre 2008. Sitio web: http://www.canirac.org.mx/portal/132993115/principal/tmp/presentacion_pnf_canirac.pdf [Fecha de Consulta: 15 de marzo de 2009].

Sistema de Información Empresarial Mexicano (siem)" Secretaría de Economía (México), sitio web: www.siem.gob.mx [Fecha de consulta: 15 de marzo de 2009].

World Franchise Council. Sitio web. http://www.worldfranchisecouncil.org [Fecha de consulta: 15 de marzo de 2009]. 